\title{
STEM Motivasyon Ölçeğinin Türkçeye Uyarlanması: Geçerlik ve Güvenirlik Çalışması
}

\section{İsmail DÖNMEZ*}

Öz: Bu çalışmanın amacı orijinali İngilizce olan STEM (Bilim-Teknoloji-MühendislikMatematik) devam eden motivasyon ölçeğini Türkçeye uyarlayarak geçerlilik ve güvenirlik çalışmasını yapmaktır. İki İngilizce dil uzmanına ölçeği İngilizceden Türkçeye çevirmesi istenmiştir. Çevirinin Türkçeye uyarlanmasından sonra iki Türk dil uzmanına ölçeğin Türkçe hali verilmiş, anlaşırlığına ilişkin yapılan düzenlemeden sonra karşılaştırılma yapılarak, geçerliliği sağlanmıştır. Örneklemi 438 (\%54,1) kız, 372 $(\% 45,9)$ 'si erkek öğrenci oluşturmaktadır. Verilerin analizi için ölçeğin güvenirliği, doğrulayıcı faktör analizine, STEM motivasyon ölçeği ve alt boyutlarının ilişkisine yer verilmiştir. Analiz sonuçlarına göre, kabul edilebilir uyum değerleri hesaplamıştır (RMSEA=0,076, SRMR=0,01, CFI=0.89). Ölçeğin Cronbach Alpha güvenirlik katsayıs1 0,84 olarak hesaplanmıştır. Elde edilen sonuçlar bilim, teknoloji, mühendislik ve matematik olmak üzere 4 boyuttan ve 25 maddeden oluşan STEM motivasyon ölçeğinin ortaokul öğrencilerine yönelik motivasyon STEM alanları çalışmalarında kullanılabilecek geçerli ve güvenilir bir araç olduğuna işaret etmektedir.

Anahtar Kelimeler: STEM, Motivasyon, Ölçek, Kariyer, Ortaokul

\section{Adaptation of STEM Motivation Scale into Turkish: Validity and Reliability Study}

Abstract: The aim of this study is to make the validity and reliability study of STEM (Science-Technology-Engineering-Mathematics) Continuing Motivation Scale. Two English language experts were asked to translate the scale from English into Turkish. Following the adaptation of the translation into Turkish, two Turkish language experts were given the Turkish version of the scale, and after the arrangement regarding the agreement, the validity was achieved by comparing. The sample consisted of $438(54.1 \%)$

*Dr. Öğr. Üyesi, Muş Alparslan Üniversitesi, Çocuk Gelişimi Bölümü Email: i.donmez@alparslan.edu.tr Orcid No: 0000-0002-7792-0169 
girls and $372(45.9 \%)$ boys. For the analysis of the data, reliability of the scale, exploratory and confirmatory factor analysis, STEM motivation scale and its subdimensions were included. According to the results of the analysis, it has calculated acceptable fit values $(\mathrm{RMSEA}=0.076, \mathrm{SRMR}=0.01, \mathrm{CFI}=0.89)$. The Cronbach's alpha reliability coefficient of the scale was calculated as 0,84 . The results indicate that the STEM motivation scale consisting of 4 items and 25 items, science, technology, engineering and mathematics, is a valid and reliable tool that can be used in the studies of motivation STEM fields for middle school students.

Keywords: STEM, Motivation, Scale, Career, Middle School

\section{Giriş}

Modern toplumlardaki örgün eğitim kurumlarının temel amacı kültürel mirası ve sosyal hayatı iletmek, aracılık etmek ve dönüştürmektir (Fred, 2006). Bu dönüşüm sürecinde ülkeler eğitimi, ekonomik gelişmişliğin bir katma değer unsuru olarak görmektedir (National Research Council [NRC], 2011). Ülkeler için ekonomik gelişmişliğin göstergelerinden biri de bilim, teknoloji alanında söz sahibi olmasıdır. Bilimsel ve teknolojik alanda söz sahibi olabilmek için STEM (bilim, teknoloji, mühendislik ve matematik) eğitimi son yıllarda bir çözüm olarak görülmektedir. 21. Yüzyıl'da gelişmiş ülkeler STEM okuryazarlığı ile bilimsel alanda önderlik ve ekonomik büyümeyi hedeflemektedir (Lacey \& Wright, 2009). STEM'in fen, teknoloji, mühendislik ve matematik alanlarında akademik içerik ile gerçek dünya durumları arasında ilişki kuran, bu içeriği okul, toplum, iş ve küresel girişimleri de dâhil eden, STEM okuryazarlığı ile yeni ekonomik rekabet koşulların gelişimini sağlayan disiplinler arası bir yaklaşımdır (Tsupros, Kohler \& Hallinen, 2009). STEM okuryazarlığı öğrencilerin kişisel karar verme, sivil ve kültürel işlere katılım ve ekonomik verimlilik için gerekli bilimsel ve matematiksel kavramların ve süreçlerin bilgi ve anlayışı olarak tanımlanmaktadır (NRC, 2011). Bilim, teknoloji, mühendislik ve matematik (STEM) eğitimine yönelik dünya çapında artan bir ilgi olduğu görülmektedir. Özellikle son 10 yıl içerisinde Amerika'da STEM eğitimi bir devlet politikası haline gelmiş ve bunun neticesinde Amerika'da çoğu eyalette STEM okulları açılmış, bu okullarda "Yeni Nesil Bilim Standartları STEM” öğretim programını uygulanmıştır. Bu okullarda proje tabanlı eğitim, mühendislik becerileri ve 21. yüzyıl becerileri ön planda tutulmaktadır (Akgündüz 
vd., 2015). Yurtdışında yaşanan bu değişimlerin ülkemizde eğitim programlarına etki ettiği görülmektedir. 2018 yılında yenilenen fen eğitim programından STEM eğitimine atıf yapılmış, mühendislik becerilerine yer verilmiştir (MEB, 2018). Disiplinler arası bir eğitim ile STEM pedagojisinin öğretim programlarında yer alması (Gomez \& Albrecht, 2013), gelecekte iş gücü ihtiyacını karşılayabilme ve toplumun tüm üyelerine STEM alanlarına yönelik iş imkânı sağlayabilmede anahtar rol oynayacaktır. Okul sistemi ilkokul ve ortaokul düzeyinde öğrencilerin STEM içeriklerine yönelik firsatlar yaratırsa, öğrencilerin STEM alanlarında eğitimlerini sürdürmelerini, dahası ileride STEM alanlarında kariyer yapmalarını sağlayacaktır (Reider, Knestis \& Malyn-Smith, 2016). STEM eğitiminin amacı, STEM alanlarında eğitim görecek öğrencilerin gelecekte iş gücünü karşılamaları olarak düşünülmektedir.

Öğrencilerin ileriki yıllarda seçecekleri mesleklerin ilköğretim zamanında oluştuğu bilinmektedir (Auger, Blackhurst \& Herting 2005). Ancak bazı öğrenciler ilkokul döneminde bilime olan ilgisini kaybetmeye başlarlar (Baird \& Penna 1992; Keeley, 2009). 10-14 arası öğrencileri STEM faaliyetlerine (Maltese \& Tai, 2011; Christensen \& Knezek, 2013) katılım sağlamaları ve STEM alanlarındaki kariyer seçeneklerine (Super, 1990) ilişkin tutum ve inançları geliştirme konusunda kritik bir aşamadır. Dolayısıyla bu süreçte öğrencilerin sınıf içi ve sınıf dışı uygulamalarla STEM alanlarına ilişskin deneyimler kazanması sağlanmalıdır (Maltese \& Tai, 2011). Yapılan araştırmalara rağmen STEM'in doğası ve STEM alanlarına olan ilginin artması için yapılan çalışmalar yetersizdir (Falk, Staus, Dierking, Penuel, Wyld \& Bailey, 2016).

Fen eğitimi literatüründe fen, teknoloji, mühendislik ve matematik (STEM) alanlarında derslerine katılımın düşük olduğu konusunda yaygın bir inanış bulunmaktadır (Osborne, Simon ve Collins, 2003; Osborne, Simon ve Tytler, 2009). Bu katılımı sağlamada motivasyonun bir çözüm olduğu birçok araştırmada dile getirilmiştir (Rosenzweig \& Wigfield, 2016; Master, Cheryan, Moscatelli, ve Meltzoff, 2017; Restivo, Chouzal, Rodrigues, Menezes, ve Bernardino Lopes, 2014).

Motivasyon, davranışta bulunma niyeti olarak tanımlanmaktadır (Elliot \& Covington, 2001). Alan eğitiminde farklı motivasyon teorileri geliştirilmiştir (Schunk, Pintrich \& Meece, 2008), bazı çalışmalar öğretimde öz-yeterliliğe odaklanırken (Wang \& Tsai, 2016) bazı çalışmalar ise motivasyon-başarı (Abraham \& Barker, 2014) ilişkisine odaklanmıştır. Araştırmalar, öğrencilerin öğrenmeye yönelik motivasyonları ile 
akademik başarıları arasında anlamlı bir ilişki olduğunu göstermiştir (ManolopoulouSergi, 2004; Schick \& Phillipson, 2009). Motivasyonu yüksek olan öğrenciler genellikle iyi bir akademik başarı kazandıkları, düşük başarı gösterenlerin ise öğrenme sürecinde yeterli motivasyona sahip olmadıkları ifade edilmektedir (Linnenbrink \& Pintrich, 2002). Wu, Tuan, Hsieh \& Chin (2013). Öğrencilerin okulda fen öğrenme konusundaki motivasyonlarını araştırdıklarında; düşük başarı gösterenlerin beklenti, değer ve davranış yönünden düşük başarı gösterenlere göre anlamlı derecede düşük performans gösterdiği görülmüştür. Bir diğer araştırmada ise fen derslerinde öğrencilerin öğrenme motivasyonlarının okuldaki notları arttıkça azaldığını da belirtmektedir (Carreira, 2011; Tuan, Chin \& Shieh, 2005). Bu nedenle, fen eğitimcilerinin, özellikle düşük başarı gösterenler için öğrencilerin öğrenme motivasyonlarını etkili bir şekilde artırmanın bir yolunu bulmaları gerekmektedir.

Ortaöğretimden yükseköğretime geçişte, birçok öğrenci için zorlu bir süreç olduğundan (Briggs, Clark \& 2012; Christie, Cree, Hounsell \& McCune, 2008), öğrencilerin akademik motivasyonu ve orta öğretimden yüksek öğretime geçişte nasıl geliştiği çok önemlidir. Yapılan araştırmalar, öğrencilerin akademik motivasyonlarının süreklilik ile ilgili olduğunu göstermiştir (Vansteenkiste vd., 2010) ve motivasyon eksikliğinin eğitim öğretim sürecinde okulu bırakmada da önemli bir etken olduğu ifade edilmektedir (Vanthournout \& ark. 2012). Ayrıca, motivasyon zaman içinde farklı bağlamlarda değişebilir (Pan \& Gauvain 2012; Ratelle vd., 2004) ve akademik başarıyı arttırmada önemli bir araç olabilir (Cerasoli, Nicklin ve Ford, 2014). Öğrencilerin STEM'e yönelik tutumları, STEM konularını öğrenme ve STEM kariyeri (Maltese \& Tai, 2011) belirmede motivasyon önemli bir faktördür.

Fen eğitimi literatüründeki ana temalardan biri, öğrencilerin Fen, Teknoloji, Mühendislik ve Matematiğe (STEM) katılma konusundaki isteksizliğinin artmasıdır (Bøe, Henriksen, Lyons, \& Schreiner, 2011; Pinxten, Van Soom, Peeters, De Laet, \& Langie (2017). Motivasyonu yüksek olan öğrenciler, yıllar geçtikçe STEM alanlarına katılımlarını sürdürürken, motivasyonu düşük öğrenciler zamanla daha fazla ayrılma eğilimindedir (Skinner, Furrer, Marchand \& Kindermann, 2008). Öğrencilerin STEM'e yönelik motivasyonlarının belirlenmesi ve motivasyonlarının devamının izlenmesi STEM alanlarında başarılarını açıklamada önemli bir faktör olarak görülebilir. Maehr'e göre devam eden motivasyon, (1) sonraki bir göreve (veya görev alanına) dönme; (2) 
benzer veya değişen durumlara uyum; (3) herhangi bir dış etki olmadan ve (4) başka davranış alternatifleri mevcut olduğunda ortaya çıkan bir dizi davranış örüntüsüdür. Örneğin, otomobillerden etkilenen bir öğrenci, otomobiller hakkındaki dergileri okumayı, motorlar hakkında bilgi almak için internette arama yapmayı, araba modelleri satın almayı ve inşa etmeyi veya ilgili bir kulübe katılmayı aktif olarak seçebilir (Luo, Wang, Liu \& Zhou, 2019). Dolayısıyla öğrencilerin STEM'e yönelik devam eden motivasyon, öğrencilerin STEM faaliyetlerindekindeki rollerini yansıtan, ömür boyu STEM öğrenimlerini sürdürülmesine yardımcı olabilecek, STEM alanlarında seçimler yapmasına ve STEM ile ilgili faaliyetlere aktif katılım sağlaması ile ilgili bir süreçtir. Sürekli motivasyon, genel motivasyon anlayıșı ile birebir aynı değildir, motivasyonun aktif davranış sergisi olarak düşünülmelidir. Dışsal ödül veya kontrol güdüsünden bağımsız, bireyin bir davranışı göstermeye karşı içsel motivasyonla ilgilidir (Deci ve Ryan, 1985). STEM eğitiminde devam eden motivasyon, bireyin görünür dış baskısı olmadan ve diğer davranışlar isteğe bağlı olduğunda, aynı veya değişken bağlamlarda dış kısıtlamalardan bağımsız olarak STEM ile ilgili belirli görevlere tekrar tekrar geri döndüğü davranış biçimleri olarak tanımlanır.

Ancak her yeni kavram beraberinde o kavramın nasıl ölçüleceği konusunda bir tartışma getirir. Ülkemiz bağlamında literatüründe devam eden STEM motivasyon ile ilgili çalışma bulunmaması; özellikle öğrencilerin STEM motivasyonlarının araştırılması için bir ölçek uyarlama çalışmasının alanyazına ve bu alanda yapılacak araştırmalara katkı sağlayacağı düşünülmektedir. Bu araştırmanın amacı, Luo, Wang, Liu ve Zhou (2019) tarafından geliştirilen devam eden STEM motivasyon ölçeğinin Türkçeye uyarlanmasını yaparak geçerlik ve güvenirlik çalışmasını yapmaktır.

\section{Yöntem}

$\mathrm{Bu}$ bölümde araştırmanın örneklemi, ölçme aracı ve verilerin analizine yer verilmiştir.

\section{Evren ve Örneklem}

$\mathrm{Bu}$ çalışmanın örneklemini Muş ilinde merkez, ilçe ve köy okulları oluşturmaktadır. Muş’un merkez ilçelerinin nüfuslarına oranla belirlenen örneklem yaşa göre dağılım gösterecek şekilde seçilmiştir. Örneklemin seçiminde kolay ulaşılabilir 
olması nedeniyle tabakalı örneklem grubu ile çalışma yürütülmüştür. Bu örnekleme yöntemi, basit tesadüfî örneklemeye oranla daha küçük bir örneklem grubu ve daha düşük bir maliyetle, evreni daha yüksek derecede temsil etme olanağı sağlamaktadır (Neuman \& Robson, 2014). Araştırmanın uygulanması için İl Milli Eğitim Müdürlüğünden gerekli izinler alınmıştır. Orijinal ölçek ortaokul öğrencilerine uygulandığından dolayı, ölçme arac1 5.,6.,7. ve 8. sınıf öğrencilerine uygulanmıştır. Tablo 1.de görüldüğü üzere ölçme arac1 810 öğrenciye uygulanmıştır. Bu öğrencilerden $438(\% 54,1)$ kız, 372 (\%45,9) 'si erkek öğrencidir. Katılımcıların \%8 ‘i 66 5. sınıf öğrencileri, \%25 ‘i 2106 6. sınıf öğrencileri, \%20 ‘si 169 7. sınıf öğrencileri, \%45 ‘i 365 8. sınıf öğrencisidir.

Tablo 1. Katılımcıların sınıf ve cinsiyete göre dağılımı

\begin{tabular}{ccccccc}
\hline & & Kiz & & \multicolumn{2}{c}{ Erkek } & \multicolumn{2}{c}{ Toplam } \\
\hline Sinıf & f & \% & f & \% & f & \% \\
\hline 5.sinıf & 36 & 8 & 30 & 8 & 66 & 8 \\
6.sınıf & 19 & 24 & 11 & 27 & 20 & 25 \\
7.sinıf & 94 & 21 & 75 & 20 & 19 & 20 \\
8.sınıf & 19 & 45 & 16 & 44 & 35 & 45 \\
\hline Toplam & 438 & 100 & 372 & 100 & 810 & 100 \\
\hline
\end{tabular}

\section{Ölçme Aracı}

STEM motivasyon ölçeği Luo, Wang, Liu, ve Zhou (2019) tarafından geliştirilmiştir. Ölçek ortaokul öğrencilerinin bilim, teknoloji, mühendislik ve matematik alanlarına ilişskin devam eden motivasyonlarını belirlemek için geliştirilmiştir. Ölçek, 28 maddeden ve 4'lü likert tipte geliştirilmiştir. Maddeler Sıklıkla (4), Bazen (3), çok az (2), asla (1) olarak derecelendirilmiştir. Ölçekten en fazla 112, en az 28 puan alınabilmektedir. Ölçekte dört boyut bulunmaktadır. 1,2,3,4,5,6,7,8. maddeler bilim boyutu, $9,10,11,12,13,14,15$. maddeler teknoloji boyutunu, 16,17,18,19,20. maddeler mühendislik boyutu, 21,22,23,24,25,26,27,28. maddeler matematik boyutunu temsil etmektedir. Ölçeği geliştiren araştırmacılar ölçeğin güvenirlik katsayısını (Cronbach alfa ( $\alpha$ ) katsayısı) 0,91 olarak hesaplamışlardır.

Yazarlarla elektronik posta aracılığı ile iletişime geçilerek ölçeğin uygulanması için izin istenmiştir. Alınan izinden sonra, iki İngilizce dil uzmanına ölçeği İngilizceden Türkçeye çevirmesi istenmiştir. Çevrinin Türkçeye uyarlanmasından sonra iki Türk dil uzmanına ölçeğin Türkçe hali verilmiş, anlaşırlığına ilişkin yapılan düzenlemeden sonra karşılaştırılma yapılarak, ölçeğin geçerliliği sağlanmıştır. Orijinal ölçekte boşluk doldurma şeklinde maddelere karşılık likert ölçekte karşılık gelen ifadeler 
işaretlenmektedir. Ancak uzman görüşleri doğrultusunda, maddelerin Türkçede anlaşılabilirliği arttırmak için ifadeler boşluk verilmeden cümle olarak sunulmasına karar verilmiştir. Ölçek, iki Türkçe öğretmenine inceletilmiş, 20 okul öncesi öğretmen adayına uygulatılmış, anlaşılabilirlik ve şablondaki hatalar düzeltilmiştir. Son olarak 25 kişiden oluşan 8. sınıf öğrencisine ön uygulama yapılmış ve ölçeğe son şekli verilmiştir.

\section{Verilerin analizi}

Ölçeğin güvenirliğini belirlemek için tüm alanlar ve boyutlar için SPSS 22.0 paket program kullanılarak güvenirlik analizi yapılmıştır. Ardından maddelerin orijinal ölçekle ilişkisini incelemek AMOS 22.0 program ile doğrulayıcı faktör analizi (DFA) yapılmıştır. Bunun yanı sıra büyük örneklemlerde DFA sonucunun yorumlanmasında, büyüyen örneklemle birlikte ki-kare değeri ve serbestlik derecesi etkilenmekte, bu durum yanlış yorumların yapılmasına neden olabilmektedir (Çokluk, Şekercioğlu ve Büyüköztürk, 2012: 268). Bu nedenle DFA sonucunun yorumlanmasında ki-kare değerinin serbestlik derecesine bölümü yerine RMSEA, AGFI, SRMR, GFI uyum indekslerine yer verilmiştir.

Tablo 2.'de Ölçeğin güvenirliğine ilişkin 25 maddeden oluşan bilim, teknoloji, mühendislik, matematik boyutlarının Cronbach Alpha güvenirlik katsayısı 0,84 hesaplanmıştır. Bilim boyutunda güvenirlik katsayısı (5. madde çıkartılmıştır) 0,696 olarak hesaplanmıştır (değer 0.70'e yakın olduğunda başka madde çıkarılmamıştır). Teknoloji boyutunda güvenirlik katsayısı 0,75 , mühendislik boyutunda (21. madde çıkarılmıştır) güvenirlik katsayısı 0,72, matematik boyutunda güvenirlik katsayısı (27. madde çıkarılmıştır) 0,80 olduğu belirlenmiştir. Tüm boyutlar için güvenirlik katsayısının 0.70 ve üzerinde olması ölçeğin güvenirliği için yeterli olduğu ifade edilmektedir (Büyüköztürk, 2011). Matematik ve bilim boyutunda güvenirlik katsayısının 0.70’e çok yakın olduğu görülmektedir. Orijinal ölçekte ise güvenirlik katsayıları bilim boyutu için 0.838, Teknoloji boyutu için 0.793, Mühendislik boyutu için 0.863 ve Matematik boyutu için 0.757 olarak hesaplanmıştır. Tüm ölçeğin güvenirlik katsayısı 0,91 olarak bulunmuştur. Dolayısıyla orijinal ölçek ile Türkçe 'ye uyarlanan ölçek arasında yakın değerlere ulaşıldı̆̆ı görülmektedir. 
YYÜ Eğitim Fakültesi Dergisi (YYU Journal of Education Faculty), 2020; 17(1):486-510, http://efdergi.yyu.edu.tr ,

Tablo 2. Ölçeğin güvenirlik katsayıları

\begin{tabular}{ccc}
\hline Boyut & Madde Sayısı & Güvenirlik katsayısı \\
\hline Bilim & 6 & 0,69 \\
Teknoloji & 7 & 0,72 \\
Mühendislik & 5 & 0,72 \\
Matematik & 7 & 0,80 \\
STEM Motivasyon & 25 & 0,84 \\
\hline Ölçekte olumsuz maddeler bulunmaktadır Bunlardan; 3. Madde anlam itibari ile
\end{tabular}
olumsuz bir ifade olduğundan dolayı ters kodlanmıştır.

\section{Bulgular}

\section{Doğrulayıcı Faktör Analizi}

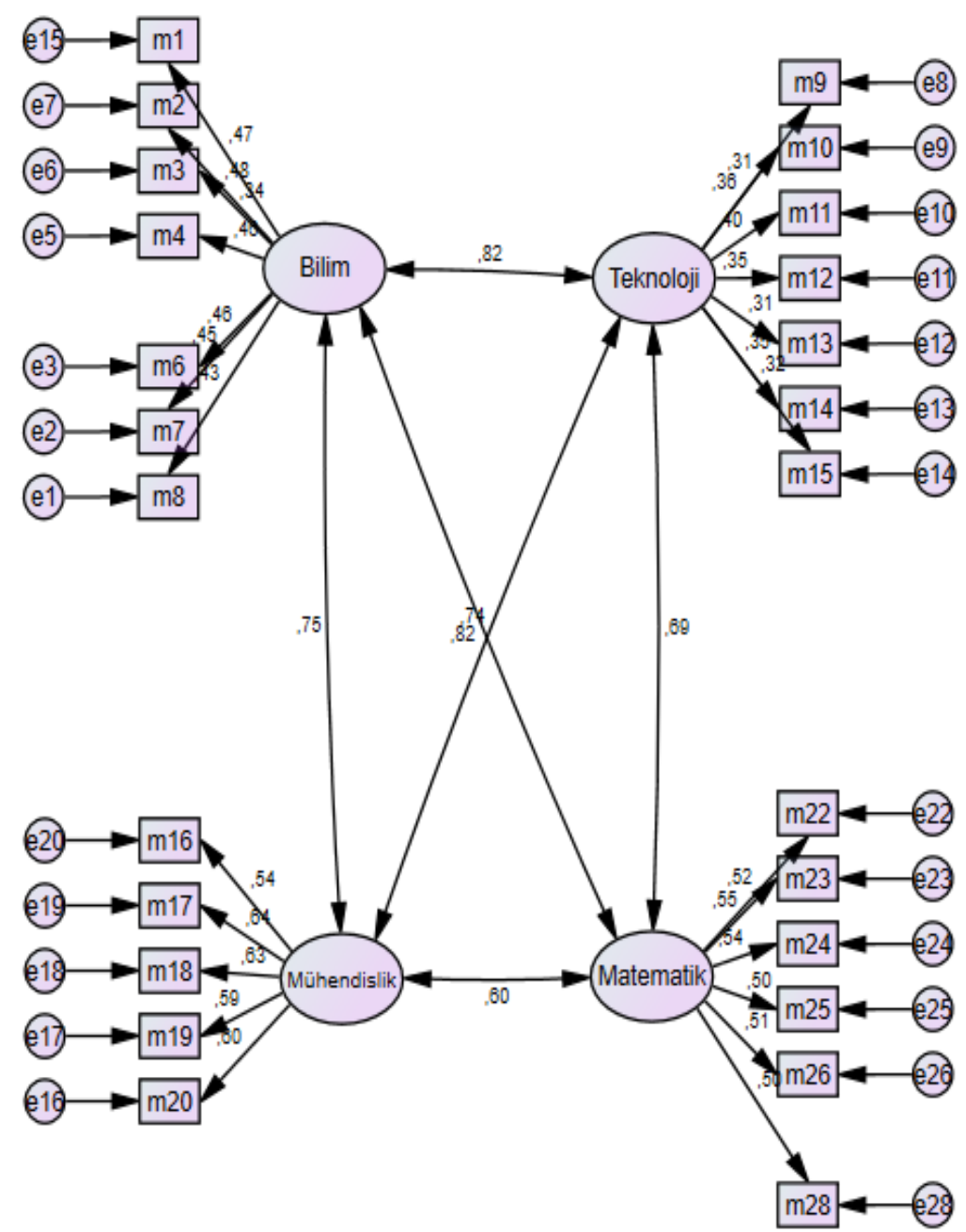

Şekil 1. Doğrulayıcı Faktör Analizi 
Şekil 1.de doğrulayıcı faktör analizi değerleri görülmektedir. Bilim boyutunda 0.34 ila 0,49 arasında, teknoloji boyutunda 0,31 ila 0,40 arasında, mühendislik boyutunda 0,54 ila 0,60 , matematik boyutunda 050 ile 0,52 arasında değiştiği görülmektedir. Boyutlar arasındaki kolerasyon; bilim ve teknoloji boyutu arasında 0,82; bilim is mühendislik arasında 0,75 ; mühendislik ve matematik arasında 0,60 ; matematik ile teknoloji arasında 0,69 ; bilim ile matematik arasında 0,74 ; teknoloji ile mühendislik arasında 0,82 olduğu görülmektedir. Kline (2005), 0,30 dolayındaki etki değerinin 'orta'; 0,50 ve üzeri etki değerinin 'yüksek' düzeyde olduğunu ifade etmektedir. Modelde de görüldüğü üzere etki değerlerinin hepsi 0,30’un üzerindedir ve boyutlar arasındaki etki değerinin yüksek olduğu görülmektedir.

Ölçek uyarlama çalışmalarında en sık karşılaşılan sorun açımlayıcı ve doğrulayıcı faktör analizi yöntemlerinden hangisinin tercih edileceğidir (Özcan \& Kara, 2018). Ölçek uyarlama çalışmalarında, orijinal ölçeğin belli bir faktör yapısına sahip bulunması nedeniyle doğrulayıcı faktör analizinin kullanımı daha uygun görünmektedir (Fabrigar, Wegener, MacCallum ve Strahan, 1999).

Tablo 3. Açımlayıcı ve Doğrulayıcı faktör analizi değerleri

\begin{tabular}{|c|c|c|c|}
\hline & & Önerilen Değerler & STEM Motivasyon Ölçeği \\
\hline & Madde sayısı & - & 25 \\
\hline \multirow{5}{*}{ 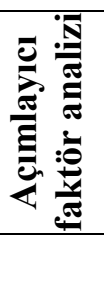 } & Boyut say1s1 & - & 4 \\
\hline & Cronbach alpha & $\geq 0,70$ & 0,84 \\
\hline & KMO & 1'e yakın & 0,87 \\
\hline & Bartlett anlamlılık testi & 0’a yakın & 0,000 \\
\hline & $X^{2} / \mathrm{df}$ & $3-5$ & 0,10 \\
\hline \multirow{5}{*}{ 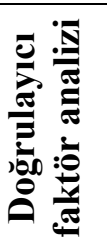 } & p-değeri & $<0,05$ & 0,000 \\
\hline & RMSEA & $\leq 0,08$ & 0,076 \\
\hline & SRMR & $\leq 0,08$ & 0,01 \\
\hline & CFI & $0,80-0,89$ & 0,89 \\
\hline & AGFI & $0,80-0,89$ & 0,82 \\
\hline
\end{tabular}

Tablo 3'te açımlayıcı faktör analizi değerleri görülmektedir. Cronbach alpha güvenirlik katsayısı 0,84 olduğu görülmektedir. $\mathrm{Bu}$ değerin 0.70 'ten büyük olması güvenirlik için yeterli olduğu ifade edilmektedir. Açıklayıcı faktör analizinde KaiserMeyer- Olkin (KMO) değeri, Bartlett Boyutsallık testinin anlamlılık düzeyi, özdeğerlikmadde grafiği, maderlerin toplam varyans değerleri 0.87 bulunmuştur $(p=0.00)$. KMO değeri, 1'e yakın bir değer olması ile çalışma grubunun sayısının yeterli olduğunu, Bartlett Boyutsallık testinin 0,000 ile anlamlı çıkması ile verilerin faktör analizine uygun olduğunun bir göstergesi olarak kabul edilmektedir (Büyüköztürk, 2007). Ölçekte $X^{2} / \mathrm{df}$ 
(ki-kare) değeri 0,10 olarak hesaplanmıştır. Doğrulayıcı faktör analizi için RMSEA, AGFI, SRMR, CFI, AGFI değerlerine bakılmıştır. RMSEA değeri 0,076 $(\leq 0,08)$, SRMR değeri $0,01(\leq 0,08)$, CFI değeri $0,89(0,80-0,89)$, AGFI değeri $0,82(0,80-0,89)$ olarak hesaplanmıştır. Alanyazına göre GFI ve AGFI değerlerinin, 0,80- 0,89 (Segars ve Grover 1993; Doll, Weidong, Gholamreza, 1994) arasında olması kabul edilebilir değerler olarak ifade edilmektedir.

\section{STEM Motivasyon Ölçeği ve Alt Boyutlarının İlişkisi}

Tablo 4’te STEM Motivasyon Ölçeği ve alt boyutlarının ilişkisi görülmektedir. Pearson kolerasyon analizine göre STEM motivasyon ölçeği ile bilim boyutu arasından 0,797 $(\mathrm{p}<0,001)$, STEM motivasyon ölçeği ile teknoloji boyutu arasından 0,720 ( $p<0,001)$, STEM motivasyon ölçeği ile mühendislik boyutu arasından 0,751 ( $<<0,001)$, STEM motivasyon ölçeği ile matematik boyutu arasından 0,797 ( $<<0,001)$ kolerasyon hesaplanmıştır. Tüm boyutlar arasında pozitif yönde güçlü bir kolerasyon olduğu görülmektedir.

Tablo 4. STEM motivasyon ölçeği ve alt boyutlarının ilişkisi

\begin{tabular}{|c|c|c|c|c|c|}
\hline \multirow{4}{*}{$\begin{array}{c}\text { STEM } \\
\text { Motivasyon } \\
\text { Ölçeği }\end{array}$} & Kolerasyon & $\begin{array}{c}\text { Bilim } \\
\text { Boyutu }\end{array}$ & $\begin{array}{c}\text { Teknoloji } \\
\text { Boyutu }\end{array}$ & $\begin{array}{c}\text { Mühendislik } \\
\text { Boyutu }\end{array}$ & $\begin{array}{c}\text { Matematik } \\
\text { Boyutu }\end{array}$ \\
\hline & Pearson Correlation &, $797^{* *}$ &, $720^{* *}$ &, $751^{* *}$ & ,751** \\
\hline & Sig. (2-tailed) &, 000 & ,000 &, 000 &, 000 \\
\hline & $\mathrm{N}$ & 810 & 810 & 810 & 810 \\
\hline
\end{tabular}

Tablo 5. STEM motivasyon ölçeğinin alt boyutların arasındaki ilişkisi

\begin{tabular}{|c|c|c|c|c|c|}
\hline & Kolerasyon & Bilim Boyutu & Teknoloji Boyutu & Mühendislik Boyutu & Matematik Boyutu \\
\hline \multirow{3}{*}{$\begin{array}{c}\text { Bilim } \\
\text { Boyutu }\end{array}$} & Pearson Correlation & 1 &, $425^{* *}$ &, $457^{* *}$ &, $457 * *$ \\
\hline & Sig. (2-tailed) & &, 000 &, 000 &, 000 \\
\hline & $\mathrm{N}$ & 810 & 810 & 810 & 810 \\
\hline \multirow{3}{*}{$\begin{array}{l}\text { Teknoloji } \\
\text { Boyutu }\end{array}$} & Pearson Correlation &, $425^{* *}$ & 1 &, $384^{* *}$ & ,384** \\
\hline & Sig. (2-tailed) & ,000 & & ,000 & ,000 \\
\hline & $\mathrm{N}$ & 810 & 810 & 810 & 810 \\
\hline \multirow{3}{*}{$\begin{array}{c}\text { Mühendislik } \\
\text { Boyutu }\end{array}$} & Pearson Correlation &, $457^{* *}$ &, $384^{* *}$ & 1 & $406 * *$ \\
\hline & Sig. (2-tailed) & ,000 & ,000 & & ,000 \\
\hline & $\mathrm{N}$ & 810 & 810 & 810 & 810 \\
\hline \multirow{3}{*}{$\begin{array}{c}\text { Matematik } \\
\text { Boyutu }\end{array}$} & Pearson Correlation &, $457 * *$ &, $384 * *$ & ,406** & 1 \\
\hline & Sig. (2-tailed) &, 000 & ,000 & ,000 & \\
\hline & $\mathrm{N}$ & 810 & 810 & 810 & 810 \\
\hline
\end{tabular}


Tablo 5'te STEM motivasyon ölçeğinin alt boyutların arasındaki ilişkisi görülmektedir. Pearson kolerasyon analizine göre bilim boyutu ile teknoloji boyutu arasından 0,425 $(\mathrm{p}<0,001)$, bilim boyutu ile mühendislik boyutu arasından $0,457(\mathrm{p}<0,001)$, bilim boyutu ile matematik boyutu arasından 0,457 ( $<<0,001)$, teknoloji boyutu ile mühendislik boyutu arasından $0,384(\mathrm{p}<0,001)$, teknoloji boyutu ile matematik boyutu arasinda 0,384 $(p<0,001)$, mühendislik boyutu ile matematik boyutu arasında $0,406(p<0,001)$, kolerasyon hesaplanmıştır. Boyutlar arasında orta düzeyde pozitif yönde bir kolerasyon olduğu görülmektedir.

\section{Tartışma, Sonuç ve Öneriler}

STEM eğitiminin son yıllarda eğitim ortamlarında yaygınlaşmasının STEM alanlarında yetişmiş insan gücüne olan ihtiyacın bir sonucu olduğu görülmektedir (Lacey \& Wright (2009); NRC, 2011). STEM' e yönelik iş gücünün karşılanması için ders içeriklerinde STEM uygulamalarının yapılması önerilmektedir. STEM uygulamalarında öğrencilerin STEM'e yönelik tutumları, STEM konularını öğrenmeleri ve STEM kariyeri (Maltese ve Tai, 2011) alanlarına yönelmede motivasyon önemli bir faktör olduğu görülmektedir. Motivasyonu yüksek olan öğrenciler, yıllar geçtikçe STEM alanlarına katılımlarını sürdürürken, motivasyonu düşük öğrenciler zamanla STEM alanlarından data fazla ayrılma eğilimindedir (Skinner, Furrer, Marchand \& Kindermann, 2008). STEM motivasyon Zollman'ın (2012) gelecekteki vatandaşların sahip olması gerektiğini iddia ettiği STEM okuryazarlığının bir bileşenidir. Bu nedenle, STEM eğitimde devam eden motivasyon faktörü önemli bir eğitim sonucu olarak değerlendirilmelidir (Fortus ve Vedder-Weiss, 2014; Maehr, 1976).

Bu araştırmada Luo, Wang, Liu \& Zhou, (2019) tarafından geliştirilen devam eden STEM motivasyon ölçeğinin Türkçe'ye uyarlayarak geçerlilik ve güvenirlik çalışmasını yapmaktır. STEM motivasyon ölçeğinin Türkçe uyarlaması sonucunda orijinal ölçekte olduğu gibi bilim, teknoloji, mühendislik ve matematik boyutlarını olmak üzere 4 boyutlu bir yapıda olduğu görülmüştür. Ölçeğin orijinalinde olduğu gibi 4lü likert tipte düzenlemiştir. 25 maddeden oluşan ölçeğin faktör yüklerini belirlemek için doğrulayıcı faktör analizi yapılmıştır. Doğrulayıcı faktör analizi sonucunda Cronbach alpha, KMO, Bartlett anlamlılık testi uygulanmış elde edilen değerlerin yeterli olduğu görülmüştür. Doğrulayıcı faktör analizi için RMSEA, SRMR, CFI, AGFI değerlerine bakılmış, elde 
edilen değerlerin yeterli olduğu görülmüştür. STEM motivasyon ölçeğini oluşturan alt boyutlar arasında ve bu boyutlarında kendi arasında kolerasyon analizi yapılmıştır. Kolerasyon analizlerinde boyutlar arasında anlamlı bir farklılık olduğu görülmüştür. Ölçek maddelerinin uyarlamasının yapmak için öncelikle güvenirlik analizi yapılmış, üç maddenin güvenirlik katsayılarının düşük olması nedeniyle ölçekten çıkarılması uygun görülmüştür. Bilim, Teknoloji, Mühendislik ve matematik boyutları ile STEM motivasyon tümü arasında pozitif yönde güçlü bir kolerasyon olduğu görülüştür. Elde edilen sonuçlar STEM motivasyon ölçeğinin, ortaokul öğrencilerine yönelik motivasyon çalışmalarında kullanılabilecek geçerli ve güvenilir bir araç olduğuna işaret etmektedir (EK-1).

Ölçek, öğrencilerin ders içi ve ders dışı zamanlarda STEM ile ilgili şeyler yapmak için devam eden motivasyonlarını ve kariyer ilgi alanlarına yönelik seçimlerini keşfetmeye yardımcı olabilir. Sınıf seviyelerinde STEM alanlarına yönelik devam eden motivasyonların ya da cinsiyet faktörüne yönelik motivasyon çalışmalarında kullanılabilir.

Öğrencilerin STEM alanlarına yönelik içeriklere ulaşması öğrencilerin hem STEM okuryazarlığına ilişkin bilgi ve becerilerinin gelişimine katkı sunacak hem de STEM alanlarına yönelik kariyer devamlılığının oluşmasına katkı sağlayacaktır. STEM eğitiminin amaçlarına ulaşmasında motivasyon önemli bir faktör olduğu görülmektedir. Dolayısıyla STEM alanlarında öğrencilerin motivasyonlarının ölçülmesi hem akademik içeriğe katkı sunacak hem de eğiticilere öğrencilerinin motivasyonları hakkında bilgi verecektir.

\section{Makalenin Bilimdeki Konumu}

\section{STEM Eğitimi/Fen Bilgisi Eğitimi}

\section{Makalenin Bilimdeki Özgünlüğü}

Öğrencilerin STEM'e yönelik devam eden motivasyonlarını ve katılımlarını artırmak için, STEM öğrenme ortamında hangi faktörlerin destekleyebileceğini araştırmak önemlidir. Ancak her yeni kavram beraberinde o kavramın nasıl ölçüleceği konusunda bir tartışma getirir. Ülkemiz ölçeğinde STEM motivasyon ile ilgili çalışma bulunmaması özellikle öğrencilerin STEM motivasyonlarının araştırılması için bir ölçek uyarlama çalışması literatürdeki eksikliğe katkı sağlayacağı düşünülmektedir. Bu 
YYÜ Eğitim Fakültesi Dergisi (YYU Journal of Education Faculty), 2020; 17(1):486-510, http://efdergi.yyu.edu.tr ,

araştırmada Luo, Wang, Liu \& Zhou (2019) tarafından geliştirilen STEM motivasyon ölçeğinin Türkçeye uyarlanmasını yaparak geçerlik ve güvenirlik çalışması yapılmıştır. Elde edilen sonuçlar STEM motivasyon ölçeğinin ortaokul öğrencilerine yönelik devam eden motivasyon alanları için kullanılabilecek geçerli ve güvenilir bir araç olduğuna işaret etmektedir Öğrencilerin STEM alanlarına yönelik içeriklere ulaşması öğrencilerin hem STEM okuryazarlığına ilişkin bilgi ve becerilerinin gelişimine katkı sunacak hem de STEM alanlarına yönelik kariyer devamlılığının oluşmasına katkı sağlayacaktır. 


\section{Kaynaklar}

Abraham, J., \& Barker, K. (2014). Sustaining young people's enrolment intentions in relation to Physics: Development and validation of a tool. Australian Journal of Educational \& Developmental Psychology, 14, 93-116.

Akgündüz, D., Aydeniz, M., Çakmakçı, G., Çavaş, B., Çorlu, M., Öner, T., \& Özdemir, S. (2015). STEM Eğitimi Türkiye Raporu: "Günümüz Modası mı Yoksa Gereksinim mi? ". $\quad$ http://www.aydin.edu.tr/belgeler/IAU-STEM-Egitimi-Turkiye-Raporu2015.pdf sayfasından erişilmiştir.

Auger, R. W., Blackhurst, A. \& Herting Wahl, K. (2005). The development of elementaryaged children's career aspirations and expectations. Professional School Counseling, 8(4), 322-329.

Baird J. R. \& Penna C. (1992). Shared adventure: a view of quality teaching and learning Second report of the teaching and learning science in schools Project. Monash University, Melbourne, pp. 185-274.

Bøe, M. V., Henriksen, E. K., Lyons, T., \& Schreiner, C. (2011). Participation in science and technology: Young people's achievement-related choices in late-modern societies. Studies in Science Education, 47, 37-72.

Briggs, A. R. J., Clark, J., \& Hall, I. (2012). Building bridges: understanding student transition to university. Quality in Higher Education, 18(1), 3-21. https://doi.org/10.1080/1343822.2011.614468.

Büyüköztürk, Ş. (2007). Sosyal bilimler için veri ve analizi el kitabl: istatistik, araştırma deseni, SPSS uygulamalart ve yorum, Anı Yayınc1l1k: Ankara.

Büyüköztürk, Ş. (2011). Sosyal Bilimler İçin Veri Analizi El Kitabı. Ankara: Pegem Akademi.

Carreira, J. M. (2011). Relationship between motivation for learning EFL and intrinsic motivation for learning in general among Japanese elementary school students. System: An International Journal of Educational Technology and Applied Linguistics, 39(1), 90-102. 
Cerasoli, C. P., Nicklin, J. M., \& Ford, M. T. (2014). Intrinsic motivation and extrinsic incentives jointly predict performance: a 40-year meta-analysis. Psychological Bulletin, 140(4), 980-1008. https://doi.org/10.1037/a0035661.

Christensen, R., Knezek, G., (2015). Active learning approaches to integrating technology into middle school science classrooms: reconceptualizing a middle school science curriculum based on 21 st century skills. Spector, J. M. (eds). Full steam ahead: emerging technologies for STEAM. Springer Academic, New York.

Christie, H., Tett, L., Cree, V. E., Hounsell, J., \& McCune, V. (2008). 'A real rollercoaster of confidence and emotions': learning to be a university student. Studies in Higher Education, 33(5), 567-581. https://doi.org/10.1080/03075070802373040.

Çokluk, Ö., Şekercioğlu, G., Büyüköztürk, Ş. (2010). Sosyal bilimler için çok değişkenli istatistik: SPSS ve LISREL uygulamalar. Ankara: Pegema

Deci, E., \& Ryan, R. M. (1985). Intrinsic motivation and self-determination in human behavior. Berlin: Springer Science \& Business Media

Doll, W. J. Weidong, X., Gholamreza, T. (1994). A confirmatory factor analysis of the end-user computing satisfaction instrument, MIS Quarterly, 18 (4), 453-461.

Elliot, A. J., \& Covington, M. V. (2001). Approach and avoidance motivation. Educational Psychology Review, 13(2), 73-92.

Rosenzweig, E. Q. \& Wigfield, A. (2016). STEM motivation interventions for adolescents: a promising start, but further to go, Educational Psychologist, 51(2), 146-163, DOI: 10.1080/00461520.2016.1154792

Fabrigar, L. R., Wegener, D. T., MacCallum, R. C. ve Strahan, E. J. (1999). Evaluating the use of exploratory factor analysis in psychological research. Pscyhological Methods, 4(3), 272-299.

Falk, J. H., Staus, N., Dierking, L. D., Penuel, W., Wyld, J. \& Bailey, D. (2016). Understanding youth STEM interest pathways within a single community: the Synergies project, International Journal of Science Education, Part B, 6(4), 369384,DOI: $10.1080 / 21548455.2015 .1093670$

Fortus, D., \& Vedder-Weiss, D. (2014). Measuring students' continuing motivation for science learning. Journal of Research in Science Teaching, 51(4), 497-522. doi:10.1002/tea.21136 
Gomez, A. ve Albrecht, B. (2014). True STEM education. Technology and Engineering Teacher, 73 (4), 8-16.

Özcan, H., \& Koca, E. (2019). STEM'e yönelik tutum ölçeğinin Türkçeye uyarlanması: Geçerlik ve güvenirlik çalışması. Hacettepe Üniversitesi Eğitim Fakültesi Dergisi, 34(2), 387-401. doi: 10.16986/HUJE.2018045061

Lacey A. L. \& Wright B. (2008). Occupational employment projection. Monthly Labor Review,(132)82, 82-132.

Fend, H. (2006). Neue Theorie der Schule. Einführung in das Verstehen von Bildungssystemen. Wiesbaden, DE: VS Verlag für Sozialwissenschaften

Keeley, P. (2009). Elementary science education in the K-12 system. NSTA Reports. http://nsta.org/publications/news/ story.aspx?id=55954 adresinden, 1 Ocak 2017 tarihinde alınmıştır.

Kline, R. B. (2005). Principles and practice of structural equation modeling. New York: Guilford Press.

Linnenbrink, E., \& Pintrich, P. R. (2002). Achievement goal theory and affect: An asymmetrical bi-directional model. Educational Psychologist, 37, 69-78.

Luo, T., Wang, J., Liu, X., \& Zhou, J. (2019). Development and application of a scale to measure students' STEM continuing motivation. International Journal of Science Education, 41(14), 1885-1904. doi: 10.1080/09500693.2019.1647472

Pan, Y., \& Gauvain, M. (2012). The continuity of college students' autonomous learning motivation and its predictors: a three-year longitudinal study. Learning and Individual Differences, 22(1), 92-99. https://doi. org/10.1016/j.lindif.2011.11.010

Pinxten, M., Van Soom, C., Peeters, C., De Laet, T., \& Langie, G. (2017). At-risk at the gate: Prediction of study success of first-year science and engineering students in an open-admission university in Flanders-Any incremental validity of study strategies? European Journal of Psychology of Education, 34, 45-66.

Ratelle, C. F., Guay, F., Larose, S., \& Senécal, C. (2004). Family correlates of trajectories of academic motivation during a school transition: a semiparametric group-based approach. Journal of Educational Psychology, 96(4), 743-754. https://doi.org/10.1037/0022-0663.96.4.743. 
Reider, D., Knestis, K. \& Malyn-Smith, J. (2016). Workforce education models for K-12 STEM education programs: Reflections on, and implications for, the NSF ITEST program. Journal of Science Education and Technology, 25(6), 847-858.

Maehr, M. L. (1976). Continuing motivation: An analysis of a seldom considered educational outcome. Review of Educational Research, 46(3), 443-462. doi:10.3102/ 00346543046003443

Maltese A.V., Tai R.H., (2011). Pipeline persistence: examining the association of educational experiences with earned degrees in STEM among U.S. students. Science Education,95(5):877-907.

Manolopoulou-Sergi, E. (2004). Motivation within the information processing model of foreign language learning. System, 32(3), 427-441.

Master, A., Cheryan, S., Moscatelli, A., \& Meltzoff, A. N. (2017). Programming experience promotes higher STEM motivation among first-grade girls. Journal of Experimental Child Psychology, 160, 92-106.

Milli Eğitim Bakanlığı (2018). Fen Bilimleri Dersi Öğretim Programı. Ankara.

National Research Council [NRC]. (2011). National science education standards. Washington, DC: National Academy.

Neuman, W. L. \& Robson, K. (2014). Basics Of Social Research. Toronto: Pearson Canada.

Osborne, J., Simon, S., and Collins, S. (2003). Attitudes towards science: A review of the literature and its implications. International Journal of Science Education, 25(9), $1049-1079$.

Osborne, J., Simon, S. \& Tytler, R. (2009). Attitudes toward science: An update. Paper presented in Annual Meeting of the American Educational Research Association, San Diego, California.

Restivo, T., Chouzal, F., Rodrigues, J., Menezes, P. and Bernardino Lopes, J. "Augmented reality to improve stem motivation," in IEEE Global Engineering Education Conference, Istanbul, Turkey, April 2014, pp. 803-806.

Segars, A. H. \& Grover, V. (1993). Re-examining perceived ease of use and usefulness: a confirmatory factor analysis, MIS Quarterly, 17 (4), 517-525. 
Schick, H., \& Phillipson, S. N. (2009). Learning motivation and performance excellence in adolescents with high intellectual potential: What really matters? High Ability Studies, 20(1), 15-37.

Schunk, D. H., Pintrich, P. R., \& Meece, J. L. (2008). Motivation in education: Theory, research and application. Columbus, $\mathrm{OH}$ : Pearson.

Skinner, E., Furrer, C., Marchand, G., \& Kindermann, T. (2008). Engagement and disaffection in the classroom: Part of a larger motivational dynamic? Journal of Educational Psychology, 100(4), 765-781.

Super, D. E. (1990). A Life Span, Life Space Approach to Career Development. In D. Brown \& L. Brooks (Edit.) Career Choice and Development: Applying Contemporary Theory to Practice (s.197-261). San Francisco: Jossey-Bass.

Tsupros, N., Kohler, R., \& Hallinen, J. (2009). STEM education: A project to identify the missing components. Intermediate Unit 1 and Carnegie Mellon.

Tuan, H. L., Chin, C. C., \& Shieh, S. H. (2005). The development of a questionniare to measure students' motivation toward science learning. International Journal of Science Education, 27(6), 639-654.

Vansteenkiste, M., Smeets, S., Soenens, B., Lens, W., Matos, L., \& Deci, E. L. (2010). Autonomous and controlled regulation of performance-approach goals: their relations to perfectionism and educational outcomes. Motivation and Emotion, 34(4), 333-353. https://doi.org/10.1007/s11031- 010-9188-3

Vanthournout, G., Gijbels, D., Coertjens, L., Donche, V., \& Van Petegem, P. (2012). Students' persistence and academic success in a first year professional bachelor program: the influence of students' learning strategies and academic motivation. Education Research International, 2012, 1-10. https://doi.org/10.1155/2012/152747.

Wang, Y.-L., \& Tsai, C.-C. (2016). Taiwanese students' science learning self-efficacy and teacher and student science hardiness: A multilevel model approach. European Journal of Psychology of Education, 31(4), 537-555. https://doi.org/10.1007/s10212-015-0285-2.

Wu, T. Y., Tuan, H. L., Hsieh, C. H., \& Chin, C. C. (2013). The validation of the questionnaire of science teacher's perception on low-achiever's need. Paper 
YYÜ Eğitim Fakültesi Dergisi (YYU Journal of Education Faculty), 2020; 17(1):486-510, http://efdergi.yyu.edu.tr ,

presented at the Third International Conference of East-Asian Association for Science Education, Hong-Kong, China.

Zollman, A. (2012). Learning for STEM literacy: STEM literacy for learning. School Science and Mathematics, 112(1), 12-19. doi:10.1111/j.1949-8594.2012.00101.x.

\section{Summary}

\section{Statement of Problem}

One of the indicators of developed countries is what they have made in science and technology. STEM (science, technology, engineering and mathematics) education has been a solution in recent years in order to have in scientific and technological fields. In 
the 21st century, STEM literacy aims at scientific leadership and economic growth (Lacey \& Wright, 2009) in developed countries. STEM is an interdisciplinary approach that connects academic content with real-world situations in science, technology, engineering and mathematics, including the content of school, community, business and global initiatives, and enables the development of new economic competition conditions with STEM literacy (Tsupros, Kohler \& Hallinen, 2009). It is known that the career students choose in the following years occurs at the time of primary education (Auger, Blackhurst \& Herting 2005). However, some students begin to lose interest in science during primary school (Baird \& Penna 1992; Keeley, 2009). It is a critical stage for students from 10 to 14 to participate in STEM activities (Maltese \& Tai, 2011; Christensen \& Knezek, 2013) and to develop attitudes and beliefs about career options (Super, 1990) in the STEM fields. Therefore, it should be ensured that students gain experiences related to STEM fields through in-class and out-of-class practices in this process (Maltese \& Tai, 2011). Motivation is defined as intention to behave (Elliot \& Covington, 2001). The students become increasingly reluctant in participating Science, Technology, Engineering and Mathematics (STEM) (Bøe, Henriksen, Lyons, \& Schreiner, 2011; Pinxten, Van Soom, Peeters, De Laet, \& Langie, 2017) which is the focus of the science education literature. While students with higher motivation continue to participate in STEM fields over the years, students with low motivation tend to leave more and more over time (Skinner, Furrer, Marchand \& Kindermann, 2008). However, each new concept gets a discussion about how to measure to the that concept. There is no study about STEM motivation in the literature in the scope of Turkey. The purpose of this research is to make the validity and reliability study by adapting the STEM continuing motivation scale developed by Luo, Wang, Liu and Zhou (2019) into Turkish. 


\section{Method}

The original scale was applied to the middle school students, so the measurement tool was used for the 5th, 6th, 7th and 8th grade students. 810 students were applied the measurement tool. Of these students, $438(54.1 \%)$ were female and $372(45.9 \%)$ were male. $8 \%$ of the participant students were 665 th grade students, $25 \%$ were 2106 th grade students, $20 \%$ were 1697 th grade students, $45 \%$ were 3658 th grade students. Two English language experts were asked to translate the scale from English into Turkish. After the adaptation of the translation into Turkish, two Turkish language experts were given the Turkish version of the scale and the internal validity of the scale was ensured by comparison after the arrangement regarding its agreement. The scale was examined by two Turkish teachers, applied to 20 pre-school teacher candidates, and the intelligibility, errors in the template were corrected. Finally, 258 th grade students were pre-applied and the scale was finalized. Pearson Moment Correlation Coefficient calculated from two scales was calculated as $.81(\mathrm{p}=0.000)$. In order to determine the reliability of the scale, reliability analysis was performed using SPSS 22.0 package program for all areas and dimensions. Then, exploratory and confirmatory factor analysis (CFA) was performed for AMOS 22.0 program to examine the relationship between the items and the ordinal scale.

\section{Result and Discussion}

Cronbach alpha reliability coefficient was found to be 0,84 in all dimensions. In the explanatory factor analysis, Kaiser-Meyer-Olkin (KMO) value, Bartlett Dimensionality test significance level, eigenvalue-item graph, total variance values of the materials were 
YYÜ Eğitim Fakültesi Dergisi (YYU Journal of Education Faculty), 2020; 17(1):486-510, http://efdergi.yyu.edu.tr ,

found to be $0.87(\mathrm{p}=0.00)$. KMO value is considered as an indicator that the number of the study group is sufficient with a value close to 1 , and that the data are suitable for factor analysis with the Bartlett Dimensionality test being significant with 0.000 (Büyüköztürk, 2007). $\mathrm{X} 2$ / df (chi-square) value of the scale was calculated as 0.10 . The chi-square value and degree of freedom are affected, and this may lead to misinterpretations (Çokluk, Şekercioğlu \& Büyüköztürk, 2012: 268). RMSEA, AGFI, SRMR, CFI, AGFI values were analyzed for confirmatory factor analysis. The RMSEA value was $0.076(\leq 0.08)$, the SRMR value was $0.01(\leq 0.08)$, the CFI value was $0.89(0.80-0.89)$, and the AGFI value was $0.82(0.80-0.89)$. ). According to the literature, GFI and AGFI values between 0.80 0.89 (Segars and Grover 1993; Doll, Weidong, Gholamreza, 1994) are also expressed as acceptable values. According to Pearson correlation analysis, $0.797(\mathrm{p}<0.001)$ among science dimension with STEM motivation scale, $0.720(\mathrm{p}<0.001)$ among technology dimension with STEM motivation scale, $0.751(\mathrm{p}<0.001)$ among engineering dimension with STEM motivation scale, and $0.75(\mathrm{p}<0.001)$ with STEM motivation scale 0.797 (p $<0.001$ ) of the mathematical dimension was calculated. There is a positive positive correlation between all dimensions. As a result of the Turkish adaptation of STEM motivation survey, it was seen that it has a 4-dimensional structure, which is science, technology, engineering and mathematics as in the original scale. The scale is arranged in a 4-point Likert type with 25 items. The results indicate that STEM motivation scale is a valid and reliable tool so it can be used in the study of motivation STEM fields for middle school students.

\section{Ek: 1}

\section{STEM (Bilim-Teknoloji-Mühendislik ve Matematik) Motivasyon Ölçeği}


YYÜ Eğitim Fakültesi Dergisi (YYU Journal of Education Faculty), 2020; 17(1):486-510, http://efdergi.yyu.edu.tr , doi:10.33711/yyuefd.693825

Değerli öğrenciler bu ölçek sizin STEM (Bilim-Teknoloji-Mühendislik ve Matematik) kavramları hakkında görüşlerinizi almak için hazırlanmıştır. Lütfen maddeleri dikkatlice okuyunuz. Maddenin karşına X işareti koymanız yeterlidir. Anket formuna isminizi yazmayınız. Verdiğiniz yanıtlar araştırmanın amacına hizmet etmesi açısından önemlidir. Teşekkür ederiz.

Cinsiyetiniz Krz ( ) $\quad$ Erkek ( )

Yaşınız

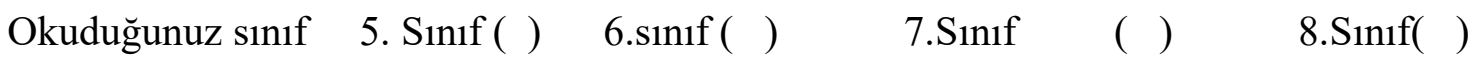

\begin{tabular}{|c|c|c|c|c|}
\hline Maddeler & S1kl1kla & Bazen & Çok az & Asla \\
\hline \multicolumn{5}{|l|}{$\begin{array}{l}\text { Bilgisayarımda bilimsel araştırmaları, bilim insanlarını, } \\
\text { doğayı veya çevre olaylarını okurum. }\end{array}$} \\
\hline \multicolumn{5}{|l|}{$\begin{array}{l}\text { Cep telefonumda bilimsel araştırmaları, bilim insanları, } \\
\text { doğa ya da çevreyi araştırırım. }\end{array}$} \\
\hline \multicolumn{5}{|l|}{$\begin{array}{l}\text { Bilimsel araştırma, bilim adamları, doğa veya çevre ile } \\
\text { ilgili bir TV şovu gördüğümde kanalı değiştiririm. }\end{array}$} \\
\hline $\begin{array}{l}\text { Bilimsel araştırmalar, bilim insanları, doğa ya da çevre } \\
\text { (bölümler dahil) hakkındaki dergi, makale ya da } \\
\text { kitaplarını okurum. }\end{array}$ & & & & \\
\hline \multicolumn{5}{|l|}{$\begin{array}{l}\text { Hayvanlar, bitkiler, gökyüzü veya diğer olaylarını } \\
\text { gözlemlerim. }\end{array}$} \\
\hline & S1klikla & Bazen & $\begin{array}{l}\text { Çok } \\
\text { az }\end{array}$ & Asla \\
\hline \multicolumn{5}{|l|}{$\begin{array}{l}\text { Bilimsel araştırmalar, bilim insanları, doğa veya çevre ile } \\
\text { ilgili TV programları izlerim. }\end{array}$} \\
\hline $\begin{array}{l}\text { Boş zamanlarımda küçük bilimsel deney tasarlarımı } \\
\text { yaparım. }\end{array}$ & & & & \\
\hline
\end{tabular}




\begin{tabular}{|c|c|c|c|c|}
\hline $\begin{array}{l}\text { Bir öğeyi kullanmayı (saat, cep telefonu veya ev aleti vb.) } \\
\text { öğrenmek için oynarım ya da içini açarım. }\end{array}$ & & & & \\
\hline $\begin{array}{l}\text { Bir öğeyi kullanmayı (saat, cep telefonu veya ev aleti vb.) } \\
\text { öğrenmek için talimatları okurum veya bilgilere erişirim. }\end{array}$ & & & & \\
\hline $\begin{array}{l}\text { Bir şeyler ters gittiğinde (bir alet bozulduğunda), nedenini } \\
\text { bulmaya çalışırım. }\end{array}$ & & & & \\
\hline $\begin{array}{l}\text { Bir yanlış gittiğinde (bir alet bozulduğunda), tamir etmeye } \\
\text { çalışırım. }\end{array}$ & & & & \\
\hline $\begin{array}{l}\text { (yeni bir alet aldığımda) aletin nasıl çalıştığını öğrenmek } \\
\text { için başkalarına sorarım. }\end{array}$ & & & & \\
\hline $\begin{array}{l}\text { Bir aletin veya ürünün üretim aşamalarını internetten } \\
\text { kontrol ederim. }\end{array}$ & & & & \\
\hline $\begin{array}{l}\text { Bir şeyler ters gittiğinde (bir alet bozulduğunda), kendim } \\
\text { çözmeye çalışmak yerine hemen yardım isterim. }\end{array}$ & & & & \\
\hline $\begin{array}{l}\text { Boş zamanlarımda modelleri, makineleri veya cihazları } \\
\text { sökmeye çalışırım. }\end{array}$ & & & & \\
\hline $\begin{array}{l}\text { (çizerek veya uygulayarak) bir alet ya da materyal } \\
\text { tasarımını geliştirmeye çalışırım. }\end{array}$ & & & & \\
\hline $\begin{array}{l}\text { Boş zamanlarımda elimdeki malzeme ve materyalleri bir } \\
\text { araya getirmeye veya yeni bir model oluşturmaya } \\
\text { çalışırım. }\end{array}$ & & & & \\
\hline & Siklıkla & Bazen & $\begin{array}{l}\text { Çok } \\
\text { az }\end{array}$ & Asla \\
\hline $\begin{array}{l}\text { Boş zamanlarımda makine veya elektrikli aletleri (çalar } \\
\text { saat, Mouse vb.) monte etmeye çalışırım. }\end{array}$ & & & & \\
\hline $\begin{array}{l}\text { Bir öğe tasarlamaya çalışıyorum (çizerek veya } \\
\text { uygulayarak) }\end{array}$ & & & & \\
\hline
\end{tabular}


YYÜ Eğitim Fakültesi Dergisi (YYU Journal of Education Faculty), 2020; 17(1):486-510, http://efdergi.yyu.edu.tr , doi:10.33711/yyuefd.693825

\begin{tabular}{|l|l|l|l|l|}
\hline Satranç veya su doku gibi hesaplama veya muhakeme & & & & \\
gerektiren matematik oyunlarını oynarım. & & & & \\
\hline Günlük yaşamdaki problemleri çözerken, tahmin & & & & \\
yeteneğimi kullanırım (mekânın büyüklüğü gibi). & & & & \\
\hline $\begin{array}{l}\text { Ders dışı matematik problemlerini bulmak için insiyatif } \\
\text { (bir kimsenin, alınması gerekli kararı öncelikle ve } \\
\text { kendiliğinden alabilmek konusundaki yeterliliği) }\end{array}$ & & & & \\
kullanırım ve çözmeye çalışırım. & & & & \\
\hline Bilgisayarımdan matematik veya matematik alanlarında & & & & \\
çalışan kişileri ararım. & & & & \\
\hline Cep telefonumdan matematik veya matematikler ile ilgili & & & & \\
içerikleri ararım. & & & & \\
\hline Matematik veya matematikçiler hakkında bir bilimsel & & & & \\
dergi ya da kitap okurum. & & & & \\
\hline
\end{tabular}

